This is an electronic reprint of the original article. This reprint may differ from the original in pagination and typographic detail.

Author(s): Björn, Piia Maria; Räikkönen, Eija; Aunola, Kaisa; Kyttälä, Minna

Title: $\quad$ Dynamics between student vs. teacher perceptions of mathematics task-orientation and mathematics performance among adolescents

Year: $\quad 2017$

Version:

Please cite the original version:

Björn, P. M., Räikkönen, E., Aunola, K., \& Kyttälä, M. (2017). Dynamics between student vs. teacher perceptions of mathematics task-orientation and mathematics performance among adolescents. Learning and Individual Differences, 55, 21-28. https://doi.org/10.1016/j.lindif.2017.02.005

All material supplied via JYX is protected by copyright and other intellectual property rights, and duplication or sale of all or part of any of the repository collections is not permitted, except that material may be duplicated by you for your research use or educational purposes in electronic or print form. You must obtain permission for any other use. Electronic or print copies may not be offered, whether for sale or otherwise to anyone who is not an authorised user. 
February 22, 2017

\begin{abstract}
This study examined the dynamics between perceptions of mathematics task-orientation and mathematics performance among Finnish adolescents over a period of two last years of secondary school. Task-orientation in math was assessed at the beginning of grade 8 and again at the end of grade 9 using both student and teacher-reports. At the same time points, students' mathematics performance was evaluated via standardized test. The cross-lagged associations of task-orientation and mathematics performance were examined taking account the possible impacts of general cognitive ability, technical reading skills, reading comprehension and gender. The results showed that a high level of mathematics performance in the beginning of 8th grade positively influenced student-rated task orientation at the end of secondary school. In turn, the anticipated reciprocal relationship between task orientation and mathematics manifested particularly in the model with teacher-rated task orientation. Implications for practice are discussed.
\end{abstract}

Keywords: task-orientation; mathematics performance; adolescence; longitudinal study 


\section{Dynamics between student vs. teacher perceptions of mathematics task-orientation and mathematics performance among adolescents}

\section{Introduction}

Children's motivation and related behavioural patterns, such as focusing on tasks at hand and persistence in the face of obstacles, has been shown to play an important role in their mathematical performance (Aunola et al., 2003, 2006). There is also some evidence that mathematics performance and task orientation form a cumulative cycle during the first years of primary school: besides that a high level of task orientation increases subsequent improvement in mathematics, also a high level of math performance increases subsequent tendency to show task orientation (Onatsu-Arvilommi et al., 2002). These kinds of results have been found among younger students when using student-ratings (Onatsu-Arvilommi et al., 2002) and teacher-ratings (Fitzpatrick \& Pagani, 2013; Hirvonen et al., 2012) of orientation. The reciprocal cycle between task orientation and mathematics performance may direct one's interest towards or away from mathematics over the years of childhood. The previous research on the topic has, however, focused on primary school students and, thus, little is known about the dynamics of task orientation and mathematics performance among secondary school students and whether such uniformity between student and teacher ratings of task orientation exists. Consequently, the present study aimed to examine the relationship between mathematics specific task orientation and mathematics performance over two latter years of secondary school employing a longitudinal approach. Both the viewpoints of teachers and the students themselves were used when assessing task orientation making it possible to examine also the extent to which there are differences in the developmental dynamics between task-orientation and mathematics performance depending on whose perception of task orientation is under concern. 


\subsection{Developmental dynamics between task-orientation and mathematics performance}

Salonen and colleagues (1998) presented several main motivational and emotional tendencies identified in real-life classroom situations (see, Lepola et al, 2004). Based on their findings, they developed an integrated model of motivational orientations and socio-emotional coping strategies. As one of the learning motivation domains, task orientation describes positive concentration ability and willingness, as well as engagement in a given task (Vauras, Lehtinen, Olkinuora, \& Salonen, 1993).

Previous research has shown that children's task orientation and mathematics performance form a cumulative cycle across early school years: task orientation is an important factor explaining subsequent mathematics performance and mathematics performance, in turn, is an important factor fostering subsequent task orientation (Aunola et al., 2003; Hirvonen, Tolvanen, Aunola, \& Nurmi, 2012; Onatsu-Arvilommi, Nurmi, \& Aunola, 2002; Sideridis \& Scanlon, 2006). Although there are studies carried out on the topic among primary school students, less is known about the dynamic between task orientation and mathematics performance among secondary school students. Entering adolescence and puberty means major changes in life and attitudes, and thus may also transform the interrelationship between task orientation and mathematics performance (Eccles et al., 1993). The other limitation of previous research is that task-orientation has been approached as general behavioral patterns evident in all learning situations. However, motivation and related constructs have been shown to be often subject-specific (Steinmayr \& Spinath, 2009). Consequently, the major aim of the present study was to examine the dynamics between task-orientation and mathematics performance among secondary school students restricting the concept 'task orientation' to the domain-specific component of one's engagement and persistence towards mathematics tasks. 


\subsection{Teachers' and students' perceptions of task orientation}

In some of the previous studies teacher-ratings of task orientation have been used (e.g. Fitzpatrick \& Pagani, 2013), whereas some other studies have used students' self-perceptions (e. g. Onatsu-Arvilommi et al., 2002). The findings that there are significant differences in teachers' and students' perceptions of task-orientation (Auwarter \& Auruguete, 2008) suggest, however, that teachers and students may rate task orientation differently. The teachers' perceptions on students' motivation and performance in mathematics have been reported as being somewhat problematic according to the context of assessment (Meece et al., 2006). By this Meece and others (2006) referred to possible situationality of the students' assessments and stronger relation to longitudinal reflections related to performance level of the students in teacher assessments.

In fact, this situationality of interest and motivation may be a key to understanding differences in teacher's and student's rating of task-orientation. Pintrich (2003) has defined situationality of interest as a psychological state of being interested in a task that is generated by that task or context. In other words, as tasks and contexts change, even during a regular school day, also students' task-orientation may be expected to vary over a period of time.

As another explanation of the anticipated differences between student and teacher ratings of task-orientation, Auwarter and Auruguete (2008) showed that teachers' perceptions of their students' motivation to learn were dependent on students' gender and SES: teachers are likely to develop negative attitudes toward low-SES students in in general, but especially toward boys. Research has also demonstrated that the teacher-student relationships are subject to changes even within one school year. For example, Gehlbach et al. (2012) investigated changes in the teacherstudent relationships over one middle school year and whether any emergent changes associated with shifts in students' academic or motivational outcomes. The findings suggested substantial changes in these relationships from the beginning to the end of the year. The changes were 
associated with shifts in achievement and motivational outcomes. Because there are major changes in life and attitudes during adolescence (Kenney-Benson et al., 2006), it is possible that during that period also task-orientation from subjective point of view is increasingly situational. At the same time adolescents may be very vulnerable and dependent on the quality of teacher-student relationship (Vauras et al., 2008). It is evident that due to their developmental phase the adolescent students go through rapidly changing orientations toward school subjects resulting in changing perceptions of task-orientation, whereas teachers very probably think about the students' overall performance in mathematics while rating the task-orientation. Based on these notions, it may be expected that particularly in adolescent samples, the student and teacher ratings of mathematics task-orientation may very well differ.

\subsection{Current study}

Overall, the major aim of this two-year longitudinal study was to investigate the dynamic interrelationship between self-evaluated vs. teacher-rated task orientation and mathematics performance during secondary school in Finnish adolescents. Secondary school is part of comprehensive school in Finland and lasts for three years (grades 7-9). Students enter secondary school (i.e., grade 7) at the age of 14 . Whether the interrelationship between task orientation and mathematics performance remain the same after controlling for general cognitive ability, text reading, and text comprehension was also investigated. Finally, whether the (cross-lagged) longitudinal interrelationship between teacher and student-rated task orientation and mathematics performance is the same for boys and girls was examined.

Based on previous literature, the interrelationship between task orientation and mathematics performance was expected to be strong and reciprocal (Aunola et al., 2006; Elliott \& Dweck, 1986; Salonen, Lehtinen \& Olkinuora, 1998). However, since motivational factors have been perceived as also situational and thus changing (Pintrich, 2003), variations in the relationship were 
deemed possible over time (Shim et al., 2008). Teacher-rated and student-rated task orientation was expected to reflect motivation towards mathematics in different ways (Meece, Glienke \& Burg, 2006), student assessments of the task-orientation expected to reflect more their situational orientation than teachers' assessments (Pintrich, 2003). When examining the potential relations between task orientation and mathematics performance, it is important to control the effects of other confounds that might be important sources of endogeneity (Undheim \& Gustafson, 1987). Consequently, the current study controlled for both general nonverbal cognitive ability (Dix \& van der Meer, 2014; Pind et al, 2003). Fluid intelligence was observed to be related to mathematics performance in the adolescent population (Dix \& van der Meer, 2014; Pind, Gunnarsdóttir, \& Jóhannesson, 2003). Dix and van der Meer (2014) further suggested that fluid intelligence was a prerequisite for mathematics performance by allocating cognitive resources relevant for reading and calculation. Also literacy skills were controlled for (Ackerman \& Dykman, 2995; Jordan et al., 2002, 2003; Kyttälä \& Björn, 2013). Also student gender was taken into account, as previous studies have shown that differences towards genders seem to exist especially in teacher ratings of student abilities and motivation (Auwarter \& Auruguete, 2008; Gehlbach et al., 2012; Meece et al, 2006).

Gender differences may be somewhat culturally related and also dependent on the measures employed in each study. However, previous literature concerning Finnish girls have been shown to perform consistently better in language-related skills than Finnish boys (Sulkunen, 2013), whereas no such stability in the difference exists mathematics skills (Kyttälä \& Björn, 2013; Björn \& Kyttälä, 2011). Based on our earlier findings of this particular data on mathematics anxiety, the boys were expected to rate their mathematics task-orientation as more positive than the girls (see, Kyttälä \& Björn, 2010). Our main result was that there was a group of Finnish girls that tended to rate high levels of math anxiety, even though they at that time performed well in mathematics. 
Based on our knowledge on the results among Finnish girls and boys, statistically significant differences in the overall modelling of the dynamics between mathematics performance and task orientation were not necessarily expected. However, we wanted to show this empirically in the present study and to produce knowledge on this matter over Finnish data.

\section{Method}

\subsection{Participants and Procedure}

The data were drawn from the MASA project (Kyttälä \& Björn, 2010), which explored the possible factors behind mathematics skill differences among Finnish adolescents. Of the 225 participants who joined the study in the beginning of their eighth grade, 218 participated in the present study (96.88\% of the original sample). This random sample consisted of students representing a variety of levels in the measured skills. The participants' age distribution was between 13 and 14 years at the baseline (birth year, 1991) because formal schooling (grade 1) in Finland starts in the year when the child turns seven. The participants came from Helsinki (Finland's capital city) and Jyväskylä (a rural town in Central Finland). Approval for the study design was obtained from the school boards in the two cities prior to any data collection. As the participants were minors, also their parents asked for an informed consent to allow participation. The sample was homogeneous in terms of ethnic and cultural backgrounds, and all the participants spoke Finnish as their native language. Compulsory school lasts for nine years in Finland, of which three last years (Grade 7, Grade 8, Grade 9) are considered as secondary school. Two latter school years (Grade 8 and Grade 9) form the time span of the present study.

The adolescents' literacy skills (e.g., text comprehension and technical reading skills as covariates in the present study) and general cognitive ability (RSPM Raven's Standard Progressive Matrices as a covariate in the present study) were tested at the beginning of their eighth grade. 
Also, their mathematics performance was tested at the beginning of eighth grade (Time 1 [T1]) and then again, at the end of the ninth grade (Time 2 [T2]; note Time 2 is used here to represent the two year time span between T1 and T2). Before each testing session for mathematics performance, the participants filled in the mathematics task-orientation questionnaire. That way, their assessment was ensured to represent their domain-specific task-orientation towards mathematics and not any other school subject, or their overall attitudes towards school, for example. The teachers also filled in the mathematics task-orientation questionnaire for each student. The teachers were carefully informed to think about each student's behavior during math lessons, not overall behavior during school tasks. However, this was not expected to be a problem, as the students were secondary schoolers, their mathematics teachers filled in the questionnaires. This way, it was expected that the teachers even did not know about the student's task-orientation towards any other school subject. The mathematics performance and literacy skills were tested in cooperation with special needs teachers. All testing took place in classrooms during normal school hours. Formal consent for participation was obtained from the caregivers, this is a standard procedure in Finland for under 18-year-old participants in research projects.

\subsection{Measures}

\subsubsection{Task-orientation}

The participants' perception of mathematics task-orientation (Salonen et al, 1994) were selfevaluated by filling in a five-point, Likert-scale questionnaire (for more precise description, see Vauras et al., 1993) in which concentration ability and enthusiasm during mathematics tasks and lessons were rated. The questionnaire is validated test material derived from a test package "Motivation, Metacognition and Mathematics" (Salonen et al., 1994). The validation of the questionnaire has been conducted among Finnish students and teachers. Both the students and teachers filled in the same questionnaire, only phrasing was a little bit different (i.e. "Think about 
your behavior vs. ...think about your student's behavior...”). The introduction text for the questionnaire was meant to guide the student/teacher to think about behavior towards mathematics or during mathematics lessons. So, this questionnaire is expected to be domain-specific. For example, in the students' questionnaire, the first item was: "I think I can concentrate to a given task and do it from the beginning to the end without being distracted" 1) never 2) seldom 3) sometimes, 4) often, 5) very often, whereas the phrasing in the teacher's questionnaire was: “The student concentrates to a given task and does it from beginning to end without being distracted." This may be detected in the student's behavior 1) never, 2) seldom, 3) sometimes, 4) often, 5) very often. Another example, student questionnaire: "I do given tasks persistently, even though they would seem hard. I want to finish the given tasks"; teacher questionnaire: "The student shows persistence and willingness to finish given tasks". There were four items in the task orientation scale. Consequently, the raw maximum score was 20. The level of task orientation was calculated as an arithmetic mean from the maximum score. Cronbach's alphas for each measurement timepoint within the present sample were 0.75 (T1); 0.76 (T2) for student ratings and 0.93 (T1); 0.96 (T2) for teacher ratings, respectively.

\subsubsection{Mathematics performance}

The group-administered, KTLT-counting skills test standardized for seventh to ninth graders (Räsänen \& Leino, 2005) has four parallel versions (A-D) for follow-up purposes. Versions A and $\mathrm{C}$ were used in this particular study. The test includes items relevant for secondary school curriculum. The test consisted of 16 basic calculation and equation tasks (e.g., 'Calculate 5.01+6.7 $=$ '). Twenty-four of the 40 tasks were word problems (e.g., 'New curtains will be purchased for the school. There are six classrooms with three windows in each. There should be two curtains for every window. How many curtains will be needed altogether?'). More precisely, the word problems represented different types, including numerical problems, measurement tasks, and 
geometry tasks. One point was given for each correct answer. The test was administered with a 40minute time limit. The internal reliability of both $\mathrm{A}$ and $\mathrm{C}$ versions in the normative data $(N=$ 1,157) was 0.88 (Räsänen \& Leino, 2005). The test also correlated significantly with other measures of mathematical skills ( $r=0.61-0.78, p<0.001$; Räsänen \& Leino, 2005).

\subsubsection{Literacy skills}

2.2.3.1 Technical reading skills were measured as a combination of two tasks from a standardized, group-administered, dyslexia-screening test for adolescents and adults (Holopainen, Kairaluoma, Nevala, Ahonen, \& Aro, 2004). The first task was to find the spelling errors. The participants were supposed to find and mark an extra, missing, or wrong letter in a word. The second task was to separate the words in which the participants were instructed to draw lines between understandable words in a word chain as fast as possible (e.g., kilpakohtiparialla [racetowardspairunder]: kilpa/kohti/pari/alla [race/towards/pair/under]). The maximum score for each task was 100, totaling 200. Each subtest had a time limit of 3 minutes and 30 seconds. The two subtest scores were further combined to form the variable "technical reading skills." Testretest reliability for the spelling-error task was reported as 0.83 , and for the separate-the-words task, it was 0.84 (Holopainen et al., 2004).

2.2.3.2 Reading comprehension was measured by using a subtest from a dyslexia-screening test for adolescents and adults (Holopainen et al., 2004). The participants read a story called The Hounds of the Village, in which 52 words were changed so that they did not fit in the story. The participants were supposed to find and underline these inappropriate words. A point was given for each correctly underlined word. The time limit for this particular subtest was 45 minutes. Cronbach's alpha for this subtest was 0.91 .

\subsubsection{General cognitive ability}


General cognitive ability was assessed by using RSPM (Raven’s Standard Progressive Matrices; Raven, Court, \& Raven, 1992) to measure analytical reasoning with abstract, visuospatial material (e.g., Carpenter, Just, \& Shell, 1990). RSPM is a nonverbal measure of abstract reasoning ability and considered a measure of fluid intelligence (Raven et al., 1992) and still a widely used psychometric test of nonverbal general ability (Gagné \& St. Père, 2002; Mackintosh, 1998). The test was completed according to standard instructions in one lesson (45 minutes) (Raven et al., 1992). A booklet including all 60 problems with an answer sheet was given to each pupil. Each item consists of a visual geometric design with a missing piece. The pupils were instructed to choose the correct piece to fulfil the design, and to mark that the number of correct piece on the answer sheet. Silence and individual work were required. The maximum score was 60.

\subsubsection{Data Analysis}

Analyses were performed by using the Mplus statistical package (version 7.0; Muthén \& Muthén, 1998-2012). Robust maximum likelihood estimator (MLR) with missing data method was used; this method is comparable to the full information maximum likelihood method in which the missing data mechanism is assumed to be missing at random (MAR). The missing data method uses all information in the data without imputing the missing values. The results in the figures are presented using standardized estimates (i.e., the variances of the observed variables are fixed to one), and only statistically significant results (i.e., $p$-value of the estimate $<0.05$ ) are presented. For descriptive purposes, gender differences in the mean levels of the covariates and study variables were examined using an additional parameter feature available in Mplus for testing the differences in the means. In addition, the maximum likelihood estimates for the correlation coefficients of the variables were computed separately for girls and boys. 
The associations between a) mathematics performance and student-rated task orientation, and b) mathematics performance and teacher-rated task orientation were analyzed using crosslagged path analyses with observed variables ${ }^{1}$. Four alternative path models were tested: 1) a stability model (Model 1, see Figure 1) that included consecutive paths from T1 to T2 for both mathematics performance and task orientation (student-/teacher-rated), and no predictive paths between performance and orientation; 2) an autoregressive model for task orientation with predictive paths from mathematics performance at T1 to task orientation at T2 (Model 2, see Figure 2); 3) an autoregressive model for mathematics performance with predictive paths from task orientation at T1 to mathematics performance at T2 (Model 3, see Figure 3); and 4) a reciprocal model with all predictive paths (Model 4, see Figure 4). The concurrent associations between the investigated constructs were also included in all tested models. Models 1-3 were nested under Model 4, while Model 1 was also nested under Models 2 and 3.

Insert Figures 1-4 about here

The overall goodness-of-fit of the estimated models was evaluated by using the $\chi^{2}$ test. An insignificant $p$-value associated with a $\chi^{2}$ value indicates a good fit of the estimated model. Additionally, the comparative fit index (CFI), Tucker-Lewis index (TLI) (Hu \& Bentler, 1999) and root mean square error of approximation (RMSEA; Steiger, 1990) were additionally used to evaluate the fit of the estimated model. The $C F I$ and $T L I$ values above 0.95 indicate a good fit of the model (Hu \& Bentler, 1999), while RMSEA values below 0.05 denote a good fit, and values from 0.06-0.08 signify a reasonable fit (Steiger, 1990).

The superiority of the nested task orientation-mathematics performance models 1-3 was examined using the Satorra-Bentler scaled $\chi^{2}$ difference test (Satorra \& Bentler, 2001), Akaike's 
information criterion (AIC; Akaike, 1987), and adjusted Bayesian information criterion (aBIC;

Yang, 2006). A significant $\chi^{2}$ difference test denotes that the model with fewer degrees of freedom (i.e., fewer constraints) fits better with the data whereas a non-significant $\chi^{2}$ difference test denotes that the model with greater degrees of freedom (i.e., more constraints) fits better with the data.

After choosing the best model separately representing the longitudinal relationships between student-rated task orientation and mathematics and for teacher-rated task orientation and mathematics, RSPM, technical reading skills, and text comprehension were controlled for by letting them to correlate with student-/teacher-rated task orientation and mathematics performance within the first time point (beginning of Grade 8).

\section{Results}

\subsection{Descriptive Results}

As shown in Table 1, gender differences were found in all covariates and in task orientation rated by teachers at T1 and T2. In almost all these measures, girls scored higher than boys. Statistically significant gender differences were not found in mathematics performance and student-reported task orientation at any time point. However, there were statistically significant differences in teacher-rated task orientation at T1, in favor of girls.

Insert Table 1 about here

All statistically significant inter correlations were positive (Table 2). In both genders, mathematics performance at T1 was associated with mathematics performance at T2. In both genders, student-rated task orientation at $\mathrm{T} 1$ was linked to task orientation at $\mathrm{T} 2$, but the 
association seemed stronger among boys than among girls. In contrast, teacher-rated task orientation measure at $\mathrm{T} 1$ was linked to task orientation at $\mathrm{T} 2$ in both genders.

Insert Table 2 about here

Mutual correlations between mathematics performance and student-rated task orientation showed that mathematics performance at $\mathrm{T} 1$ was associated with concurrent task orientation among boys only but with task orientation at T2 in both genders (Table 2). Mathematics performance at T2 was linked to concurrent task orientation in both genders. In contrast, task orientation at $\mathrm{T} 1$ was linked to mathematics performance at $\mathrm{T} 2$ among boys only. The correlations were different according to teacher-rated task orientation, as, for example, the teacher-rated task orientation was interrelated with mathematics performance at $\mathrm{T} 1$, whereas no such connection was present between student-rated task orientation and mathematics.

In both genders, covariates correlated with each other (Table 2). All covariates were also associated with mathematics performance in both genders at $\mathrm{T} 1$ and $\mathrm{T} 2$, but the associations seemed stronger among boys than girls. Higher scores in RSPM and text comprehension were associated with teacher-rated task orientation at T2 in both genders. Furthermore, a higher RSPM score was linked to student- and teacher-rated task orientation at T1 among boys only. Additionally, technical reading skills and text comprehension were not associated with task orientation at $\mathrm{T} 1$.

\subsection{Mathematics performance in relation to task orientation rated by students}

As shown in Table 3, the $\chi^{2}$ difference test showed significant differences between the stability model of student ratings (Model 1a) and Models 2a and 4a, indicating that Models 2a and 4a accounted for the data better than the stability model. Model 3a did not differ from Model 1a. To 
find the most adequate model, Models $2 \mathrm{a}$ and $4 \mathrm{a}$ were further compared. According to the $\chi^{2}$ difference test, Model 2a was as good as Model 4a. However, the AIC and aBIC values supported Model 2a. These results indicated that of the four models, the model where mathematics performance was assumed to be an antecedent of student-rated task orientation showed the best approximation with the current data.

Insert Table 3 about here

Regarding the other goodness-of-fit statistics, Model 2a showed excellent fit with the data (Table 3). As shown in Figure 5, mathematics performance showed relatively strong stability between $\mathrm{T} 1$ and $\mathrm{T} 2$. In contrast, stability of student-rated task orientation was somewhat lower. High mathematics performance and high task orientation were concurrently associated with each other at both times, and the strength of the association seemed to increase from T1 to T2. Additionally, high mathematics performance at $T 1$ predicted high task orientation at $T 2$, rated by the students, after controlling for the previous level of task orientation at T1.

Insert Figure 5 about here

Finally, we tested whether the results would remain the same if RSPM, technical reading skill, and text comprehension were controlled for. Inspection of the results showed that the results remained the same suggesting a very strong interrelationship between task-orientation and mathematics performance over two last years of secondary school.

\subsection{Mathematics performance in relation task orientation rated by teachers}


The $\chi^{2}$ difference test showed significant differences between the stability model of teacher ratings (Model 1b) and Models 2b-4b, indicating that the more complicated Models $2 b-4 b$ accounted for the data better than the simplified stability model (Table 3). This result shows some support for the situational nature of task-orientation suggested by Pintrich (2003). Further comparison of the Models $2 b-4 b$ showed that Model $4 b$ (a saturated model) was superior to the Models $2 \mathrm{~b}$ and $3 \mathrm{~b}$. Thus, the model where mathematics performance and teacher-rated task orientation were reciprocally linked to one another, showed the best approximation with the current data.

Figure 6 presents Model 4b. Both mathematics performance and teacher-rated task orientation showed relatively strong stability between $\mathrm{T} 1$ and T2. High mathematics performance and high teacher-rated task orientation were associated with each other concurrently at both times as well as over time.

Insert Figure 6 about here

Finally, we tested whether the results would remain the same if RSPM, technical reading skill, and text comprehension were controlled for. Additionally, as there was gender differences in the mean levels of the covariates and teacher-rated task orientation at T1 (see Table 1), gender were set to predict these variables. Yet, the results remained the same.

\section{Discussion}

The major aim of this two-year longitudinal study was to investigate the dynamic interrelationship between self-evaluated vs. teacher-rated task orientation and mathematics performance during secondary school in Finnish adolescents. Overall, the results showed that 
earlier, strong mathematics performance predicted high task orientation later on, confirming the existing evidence that mathematics performance and task orientation continue to form a cumulative cycle: high level of task-orientation continues to increase subsequent improvement in mathematics, also a high level of math performance continues to increase subsequent tendency to show task-orientation, as suggested by Onatsu-Arvilommi and Nurmi among young children (2000), for example.

The results thus showed that mathematics performance was an antecedent of task orientation in the Finnish adolescent data according to both student-rated task orientation and teacher-rated task orientation. The result supported our first hypothesis stating the strong interrelationship between mathematics performance and task orientation, as well as findings of previous empirical studies carried out among younger students (Hirvonen et. al., 2012; OnatsuArvilommi et. al., 2002; Sideridis \& Scanlon, 2006). Our results suggest that good mathematics performance explains subsequent high task orientation. One possible explanation for this result is that performing well in mathematics increases one's task orientation and self confidence in mathematics, which then fosters task orientation in mathematics. The results showed further that also task orientation predicted subsequent math performance: the higher the level of task orientation was at the beginning of grade 8 , the higher math performance at the end of grade 9 . This result was, however, evident only when task-orientation was rated by the teacher. Studentreported task orientation did not impact on students' subsequent math performance. Consequently, it seems that our results support the assumption that teacher's ratings of task orientation reflect the actual performance level of mathematics and vice versa throughout the two-year time span in higher extent than student-rated task orientation. This difference might be due to the situational nature of motivation often experienced by the adolescent students (Pintrich, 2003). Students may, for example, have low task orientation in some strands or school subjects, while they might rate 
their task-orientation as very high in another subject. Teacher-rated task orientation was also found to be more stable across the two school years than student-rated task orientation.

The study's next aim was to examine whether the interrelationship between student-rated task orientation and mathematics performance remained the same after general cognitive ability, text reading, and text comprehension were taken into account (see also Fletcher, 2005; Fuchs \& Fuchs, 2002; Fuchs et al., 2005; Harlaar, Kovas, Dale, Petrill, \& Plomin, 2012). As the results showed, all these covariates were statistically significant and seemingly had their own relationships with both task orientation and mathematics. For example, a high RSPM score was linked to high mathematics performance and task orientation in the beginning of the eighth grade. These findings confirmed previous results showing the covariates' relationship with mathematics performance in the adolescent population (Dix \& van der Meer, 2014; Pind et al., 2003). High scores in technical reading skills and text comprehension were associated with higher mathematics performance in the beginning of the eighth grade but not with task orientation at the same time point. Although general cognitive ability explained almost half of the variations in mathematics performance in the beginning of the second year of secondary school (see also Piña, Fuentes, Castillo, \& Diamantopoulou, 2014), the relationship between mathematics performance and task orientation remained strong in both the models including student-rated and teacher-rated task orientation (Gagné \& St. Père, 2002). This finding further confirmed the strong relationship between mathematics performance and task orientation in the Finnish adolescent-age group, as suggested by Kupari and colleagues (2013).

Finally, whether the (cross-lagged) longitudinal interrelationship between teacher and studentrated task-orientation and mathematics performance is the same for boys and girls was examined. The results concerning gender differences showed that the teacher ratings of mathematics task orientation for girls and boys dropped over the two school years, whereas the girls' own ratings for 
mathematics task orientation dropped, almost dramatically, at the end of ninth grade. Instead, the boys' self-rated task orientation was higher and showed more stability, with almost no variation during the two school years. These findings might also help to explain why girls much seldom end up to careers with mathematics knowledge needed, even though their actual performance in mathematics is equal with boys. At the end of compulsory schooling when the adolescents are supposed to do important decisions considering future schooling, girls' engagement and persistence towards mathematical tasks are seemingly low which fact is apt to effect schooling choices later on. Despite of gender differences found in the levels of task orientation, the crosslagged longitudinal interrelationship between task orientation and mathematics performance was the same for secondary school-aged boys and girls in Finland.

There are reasons for caution in attempting to generalize our results. First, we had two measurement time points in the study, including general measurements of mathematics performance (e.g. arithmetics, algebra and math word problems). It would have been interesting to know whether the student-reported level of task orientation would have stayed similar when different mathematics contexts were used (e.g., basic classroom mathematics lesson, including new vs. old content, testing situation repeated once a week over a fixed period, etc.). Second, additional measurement time points over the two years would have provided more precise information about the stability vs. situationality of the task orientation (see also Bong \& Skaalvik, 2003). In this study, we were able to observe the overall tendency in the interrelationship between mathematics performance and task orientation rated by themselves and teachers among Finnish adolescents over two latter years of secondary school. Third, the numerus of the data in the present study was relatively small. This might be one reason why the comprehensive models for girls and boys did not differ statistically, even though correlations (see Table 2) were quite different between genders. Furthermore, the small sample size prevented us from using measurement 
models of task orientation to isolate measurement error. This may have resulted in limited statistical power to detect cross-lagged associations between task orientation and mathematics performance. Providing tau equivalent Cronbach's alphas especially for the task orientation measure was not possible due to the sample size. Fourth, the test measuring reading comprehension was not typical one. However, to date, the material used in the study is the only standardized screening tool available for the adolescent population in Finland.

\section{Conclusions}

We have three ways to contribute to existing literature on the interrelationship between mathematics learning and motivation in adolescence with our results reported here. Firstly, it seems that the multidirectional theory of learning motivation (Salonen et al., 1998) and especially task orientation is applicable among Finnish adolescents. It was confirmed that task orientation and mathematics performance still result as a complex dynamic model in classroom context. Task orientation does not lose its' significance among adolescent students, instead it still has a strong role in mathematics performance. Secondly, it was of essence to include both the student ratings, as well as teacher ratings of task orientation. The situational tendency of the student assessments seemed to be confirmed to some extent, while the teacher assessments were more stable suggesting that their assessments were related to the performance level of the students. Thirdly, even though there were no clear gender differences in the main variables, it was revealed that for some reason, especially the girls perceive themselves as poorly task-oriented towards mathematics in the Finnish data (see Wu, 2014). Observations concerning assessment in secondary schools can also be made based on these aforementioned results. First, a careful analysis of the direction of the association between mathematics performance and student-rated task orientation 
suggested that mathematics performance more strongly predicted task orientation later on, than vice versa. This indicates that mathematical skills are of greater importance than motivational orientation in adolescence. Expressed differently, although it is essential for mathematics instruction to make a strong impression on students and be deemed interesting, it does not override basic mathematics skills relevant for school curricula (see also Spinath et al., 2006; Steinmayr \& Spinath, 2009) that are evidently prerequisites for high level of task orientation.

In instruction this means that the teachers should include regular assessments of taskorientation and discussions on different emotions towards the subject (see, Holm et al., 2016; Seegers et al., 2002). These types of assessments take very little time, as the students get used to the analysing situations and following short discussions. As Vauras et al. $(2008 ; 2009)$ have postulated, some shifts in task-orientation are not dangerous. But, if the general tendency in taskorientation ratings of a student becomes very negative, it will have a negative impact on learning. Then, an open discussion with these students about the reasons to the negative emotions towards mathematics might help (Kenney-Benson et al., 2006). By adding a component of selfassessments, the situational changes would be easily detectable and the teachers could find out the reason of a sudden decline in task-orientation ratings. If the decline would be due to poor scores in recent tests, repeating the content of the test in instruction might be essential for some students. This way, teachers would gradually instruct the students to enable learning for themselves.

\section{References}

Ackerman, P. T., \& Dykman, R. A. (1995). Reading-disabled students with and without comorbid arithmetic disability. Developmental Neuropsychology, 11, 351-371.

Akaike, H. (1987). Factor analysis and AIC. Psychometrika, 52, 317-332. doi: 10.1007/BF02294359

Aunola, K., Nurmi, J. -E., Lerkkanen, M.-K., \& Rasku-Puttonen, H. (2003), The role of achievement- 
related behaviors and parental beliefs in children's mathematical performance. Educational Psychology, 23(4), 403-421.

Aunola, K., Leskinen, E., \& Nurmi, J.-E. (2006). Developmental dynamics between mathematical performance, task-motivation and teachers' goals during the transition to primary school. British Journal of Educational Psychology, 76, 21-40.

Auwarter, A. E., \& Aruguete, M. S. (2008). Effects of student gender and socioeconomic status on teacher perceptions. Journal of Educational Research, 101, 242-246. http://dx.doi.org/10.3200/JOER.101.4.243-246.

Björn, P. M. \& Kyttälä, M. (2011). Family structure and academic skills among Finnish adolescents. European Journal of Psychology of Education, 26 (4), 465-477. DOI $10.1007 / \mathrm{s} 10212-011-0058$

Bong, M., \& Skaalvik, E. M. (2003). Academic self-concept and self-efficacy: How different are they really? Educational Psychology Review, 15, 1-40.

Carpenter, P. A., Just, M. A., \& Shell, P. (1990). What one intelligence test measures: A theoretical account of the processing in the Raven Progressive Matrices Test. Psychological Review, 97, 404-431.

Dix, A., \& van der Meer, E. (2014). Arithmetic and algebraic problem solving and resource allocation: The distinct impact of fluid and numerical intelligence. Psychophysiology. doi: $10.1111 /$ psyp. 12367

Dweck, C. S. \& Leggett, (1988). A Social-cognitive approach to motivation and personality. Psychological Review, 95, 2, 256-273.

Elliott, E. S. \& Dweck, C. S (1988). Goals: An approach to motivation and achievement. Journal of Personality and Social Psychology, 54, 5 -12. doi:10.1037/0022-3514.54.1.5

Fletcher, J. M. (2005). Predicting math outcomes: Reading predictors and comorbidity. Journal of 
Learning Disabilities, 4, 308-312.

Fitzpatrick, C., \& Pagani, L. (2013). Task-orientation in kindergarten pays off in later childhood. Journal of Developmental \& Behavioral Pediatrics, 34(2), 94-101.

doi: 10.1097/DBP.0b013e31827a3779

Fuchs, L. S., \& Fuchs, D. (2002). Mathematical problem-solving profiles of students with mathematics disabilities with and without comorbid reading disabilities. Journal of Learning Disabilities, 35, 563-573.

Fuchs, L. S., Compton, D. L., Fuchs, D., Poulsen, K., Bryant, J. D., \& Hamlett, C. L. (2005). The prevention, identification, and cognitive determinants of math difficulty. Journal of Educational Psychology, 97, 493-513.

Eccles, J. S., Midgley, C., Wigfield, A., Buchanan, C. M., Reuman, D., Flanagan, C., \& Mac Iver, D. (1993). Development during adolescence: The impact of stage-environment fit on young adolescents' experiences in schools and in families. American Psychologist, 48(2), 90-101. doi:http://dx.doi.org/10.1037/0003-066X.48.2.90

Gagné, F., \& St. Père, F. (2002). When IQ is controlled, does motivation still predict achievement? Intelligence, 30, 71-100. http://dx.doi.org/10.1016/S0160-2896(01)00068-X

Gehlbach, H., Brinkworth, M. E., Harris, A. D. (2012). Changes in teacher student relationships. British Journal of Educational Psychology, 82, 690-704. http://dx.doi.org/10.1111/j.2044-8279.2011.02058.x

Harlaar, N., Kovas, J., Dale, P. L., Petrill, S., \& Plomin, R. (2012). Mathematics is differentially related to reading comprehension and word decoding: Evidence from genetically sensitive design. Journal of Educational Psychology, 104, 622-635.

Hecht, S. A., Torgesen, J. K., Wagner, R. K., \& Rashotte, C. A. (2001). The relations between phonological abilities and emerging individual differences in mathematical computation 
skills: A longitudinal study from second to fifth grades. Journal of Experimental Child Psychology, 79, 192-227.

Hirvonen, R., Tolvanen, A., Aunola, K. \& Nurmi, J.-E. (2012). The developmental dynamics of task-avoidant behavior and math performance in kindergarten and elementary school. Learning and Individual Differences, 22, 715-723. http://dx.doi.org/10.1016/j.lindif.2012.05.014

Holm, M., Hannula, M. S. \& Björn, P. M. (2016). Mathematics related emotions among Finnish adolescents across different performance levels. Educational Psychology, 1 -14, http://dx.doi.org/10.1080/01443410.2016.1152354

Holopainen, L., Kairaluoma, L., Nevala, J., Ahonen, T., \& Aro, M. (2004). Lukivaikeuksien seulontamenetelmä nuorille ja aikuisille. [A screening test of reading difficulties for adolescents and adults]. Jyväskylä: Niilo Mäki Institute.

Hu, L., \& Bentler, P. M. (1999). Cutoff criteria for fit indexes in covariance structure analysis: Conventional criteria versus new alternatives. Structural Equation Modeling, 6(1), 1-55.

Jordan, N. C., Hanich, L. B., \& Kaplan, D. (2003). A longitudinal study of mathematical competencies in children with mathematics difficulties with and without co-morbid reading difficulties. Child Development, 74, 834-850.

Jordan, N. C., Kaplan, D., \& Hanich, L. B. (2002). Achievement growth in children with learning difficulties in mathematics: Findings of a two-year longitudinal study. Journal of Educational Psychology, 94, 586-597.

Kenney-Benson, G. A., Pomerantz, E. M., Ryan, A. M., \& Patrick, H. (2006). Sex difference in math performance: The role of children's approach to schoolwork. Developmental Psychology, 42, 11-26. 
Kupari, P., Välijärvi, J., Andersson, L., Arffman, I., Nissinen, K., Puhakka, E., \& Vettenranta, J. (2013). PISA 12 ensituloksia. [First-hand results of PISA 2012]. Helsinki: Opetus- ja kulttuuriministeriön julkaisuja 20.

Kyttälä, M. \& Björn, P. M. (2010). Prior mathematics achievement, cognitive appraisals and anxiety as predictors of Finnish students' later mathematics performance and career orientation. Educational Psychology, 30 (4), 431-448.

Kyttälä, M., \& Björn, P. M. (2013). The role of literacy skills in mathematics word problem skills: Controlling for visuo-spatial ability and mathematics anxiety. Learning and Individual Differences, 29, 59-66.

Lepola, J., Salonen, P., Vauras, M., \& Poskiparta, E. (2004). Understanding the development of subnormal performance in children from a motivational-interactionist perspective. In $\mathrm{H}$. Switzky (Ed)., International Review of Research in Mental Retardation: Personality and motivational systems in mental retardation (vol 28, pp. 145-189). San Diego: Elsevier Academic Press.

Mackintosh, N. J. (1998). IQ and human intelligence. Oxford: Oxford University Press. Meece, J. L., Glienke, B. B., \& Burg, S. (2006). Gender and motivation. Journal of School Psychology, 44, 351-373. http://dx.doi.org/10.1016/j.jsp.2006.04.004

Muthén, L., \& Muthén, B. (1998-2012). Mplus user's guide. Los Angeles, CA: Muthén \&Muthén.

Onatsu-Arvilommi, T., \& Nurmi, J.-E. (2000). The role of task-avoidant and task-focused behaviors in the development of reading and mathematical skills during the first school year: A cross-lagged longitudinal study. Journal of Educational Psychology, 92, 478-491.

Piña, V., Fuentes, L. J., Castillo, A., \& Diamantopoulou, S. (2014). Disentangling the effects of working memory, language, parental education and non-verbal intelligence on children's mathematical abilities. Frontiers in Psychology, 5(415), 1-12. doi: 10.3389/fpsyg.2014.00415 
Pind, J., Gunnarsdóttir, E. K., \& Jóhannesson, H. S. (2003). Raven’s Standard Progressive Matrices: New school age norms and a study of the test's validity. Personality and Individual Differences, 34, 375-386. http://dx.doi.org/10.1016/S0191-8869(02)00058-2

Pintrich, P. R. (2003). A motivational science perspective on the role of student motivation in learning and teaching context. Journal of Educational Psychology, 95, 667-686.

Raven, J. C., Court, J. H., \& Raven, J. (1992). Standard progressive matrices. Oxford: Oxford Psychologists Press.

Räsänen, P., \& Leino, L. (2005). KTLT, Laskutaidon testi luokka-asteille 7-9 (Counting skills test for grades 7-9). Jyväskylä: Niilo Mäki Institute.

Salonen, P., Lehtinen, E., \& Olkinuora, E. (1998). Expectations and beyond: The development of motivation and learning in a classroom context. In J. Brophy (Ed.), Advances in research on teaching: Expectations in the classroom (vol 7, pp. 111-150). Greenwich, CT: JAI Press.

Salonen, P., Lepola J., Vauras, M., Rauhanummi, T., Lehtinen, E., \& Kinnunen, R. (1994) Diagnostiset testit 3. Motivaatio, metakognitio ja matematiikka. Turun yliopisto: Oppimistutkimuksen keskus.[Diagnostic tests 3. Motivation, Metacognition and Mathematics].

Satorra, A., Bentler, P. M. (2001). A scaled difference chi square test statistic for moment structure analysis. Psychometrika, 66, 507-14.

Seegers, G., van Putten, C. M., \& de Brabander, C. J. (2002). Goal orientation, perceived task outcome and task demands in mathematics tasks: Effects on students' attitude in actual task settings. British Journal of Educational Psychology, 72, 365-384.

Schunk, D. H., \& Zimmerman, B. J. (1994). Self-regulation of learning and performance: Issues and educational applications. Hillsdale, NJ: Erlbaum.

Shim, S. S., Ryan, A. M., \& Anderson, C. J. (2008). Achievement goals and achievement during 
early adolescence: Examining time-varying predictor and outcome variables in growth-curve analysis. Journal of Educational Psychology, 100, 655-671.

Sideridis, G. D., \& Scanlon, D. (2006). Motivational issues in learning disabilities. Learning Disability Quarterly, 29, 131-135.

Spinath, B., Spinath, F. M., Harlaar, N., \& Plomin, R. (2006). Predicting school achievement from general cognitive ability, self-perceived ability, and intrinsic value. Intelligence, 34(4), 363374. doi:10.1016/j.intell.2005.11.004

Steinmayr, R., \& Spinath, B. (2009). The importance of motivation as a predictor of school achievement. Learning and Individual Differences, 19, 80-90.

Steiger, J. H. (1990). Structural model evaluation and modification: An interval estimation approach. Multivariate Behavioral Research, 25(2), 173-180.

Sulkunen, S. (2013). Adolescent Literacy in Europe - An Urgent Call for Action. European Journal of Education, 48(4), 528-542. doi:10.1111/ejed.12052

Undheim, J. O., \& Gustafsson, J.-E. (1987). The hierarchical organization of cognitive abilities: Restoring general intelligence through the use of linear structural relations (LISREL). Multivariate Behavioral Research, 22, 149-171.

Vauras, M., Lehtinen, E., Olkinuora, E., \& Salonen, P. (1993). Devices and desires: Integrative strategy instruction from a motivational perspective. Journal of Learning Disabilities, 26, 384-391.

Vauras, M., Salonen, P. \& Kinnunen, R. (2008). Influences of group processes and interpersonal regulation on motivation, affect and achievement. In M. L. Maehr, S. A. Karabenick \& T. C. Urdan (Eds.), Advances in motivation and achievement: Vol. 15. Social psychological perspectives, 275-314. Bingley, UK: JAI Press.

Vauras, M., Salonen, P., Lehtinen, E. \& Kinnunen, R. (2009). Motivation in school from 
contextual and longitudinal perspectives. In M. Wosnitza, S. A. Karabenick, A. Efklides \& P. Nenniger (Eds.), Contemporary motivation research: From global to local perspectives, 1-23. Gottingen and Cambridge, MA: Hogrefe \& Huber.

$\mathrm{Wu}, \mathrm{J}-\mathrm{Y}$. (2014). Gender differences in online reading engagement, metacognitive strategies, navigation skills and reading literacy. Journal of Computer Assisted Learning, 30, 252-271. Yang, C. (2006). Evaluating latent class analyses in qualitative phenotype identification. Computational Statistics \& Data Analysis, 50, 1090-1104. doi:10.1016/j.csda.2004.11.004

Footnote

${ }^{1}$ At first, gender differences in the associations between a) mathematics performance and student-rated task orientation, and b) mathematics performance and teacher-rated task orientation were examined. The gender equality was tested in both models by comparing the fit of the unconstrained model (i.e., all paths were freely estimated for boys and girls) to that of the constrained model (i.e., all paths were constrained to be equal across genders) using the SatorraBentler scaled $\chi^{2}$ test (Satorra \& Bentler, 2001). The models turned out to be the same for boys and girls. Therefore, only one model for the associations between a) mathematics performance and student-rated task orientation, and another model for b) mathematics performance and teacherrated task orientation was estimated. 
Table 1

Means $(M)$ and standard deviations (SD, in parentheses) of covariates and study variables with the test of gender differences implemented in maximum likelihood estimation in Mplus.

\begin{tabular}{|c|c|c|c|}
\hline \multirow[t]{2}{*}{ Variables } & Girls $(n=103)$ & Boys $(n=115)$ & Difference test \\
\hline & $M(S D)$ & $M(S D)$ & $p$-value \\
\hline RSPM T1 & $46.65(5.93)$ & $44.61(7.23)$ & 0.03 \\
\hline Technical reading skills T1 & $112.07(31.07)$ & $95.30(29.08)$ & $<0.001$ \\
\hline Text comprehension $\mathrm{T} 1$ & $32.57(8.41)$ & $28.64(9.59)$ & $<0.001$ \\
\hline Mathematics performance $\mathrm{T} 1$ & $20.81(5.82)$ & $22.00(6.43)$ & 0.16 \\
\hline Task orientation $\mathrm{T}^{\mathrm{a}}$ & $3.06(0.59)$ & $3.20(0.66)$ & 0.13 \\
\hline Task orientation $\mathrm{T} 1^{\mathrm{b}}$ & $3.61(0.95)$ & $3.20(0.98)$ & $<0.001$ \\
\hline Mathematics performance T2 & $25.38(7.90)$ & $25.10(8.76)$ & 0.81 \\
\hline Task orientation $\mathrm{T} 2^{\mathrm{a}}$ & $2.98(0.79)$ & $3.16(0.75)$ & 0.14 \\
\hline Task orientation $\mathrm{T} 2^{\mathrm{b}}$ & $3.46(1.02)$ & $3.05(1.04)$ & 0.01 \\
\hline
\end{tabular}


Table 2

Maximum likelihood estimates for the correlation coefficients of covariates and study variables for girls (below the diagonal) and boys.

\begin{tabular}{|c|c|c|c|c|c|c|c|c|c|}
\hline Variables & 1 & 2 & 3 & 4 & 5 & 6 & 7 & 8 & 9 \\
\hline 1 RSPM T1 & 1 & $.30 * * *$ & $.47 * * *$ & $.53 * * *$ & $.31 * *$ & $.47 * * *$ & $.48 * * *$ & $.43 * * *$ & $.25^{*}$ \\
\hline 2 Technical reading skill T1 & $.25^{*}$ & 1 & $.41 * * *$ & $.56 * * *$ & .11 & $.21 * *$ & $.42 * * *$ & $.24 *$ & .16 \\
\hline 3 Text comprehension $\mathrm{T} 1$ & $.27 * *$ & $.49 * * *$ & 1 & $.47 * * *$ & $.23^{*}$ & $.44 * * *$ & $.31 * *$ & .16 & $.28 * *$ \\
\hline 5 Task orientation $\mathrm{T}^{\mathrm{a}}$ & .07 & -.04 & .12 & .06 & 1 & $.44 * * *$ & $.27 * *$ & $.41 * *$ & $.42 * * *$ \\
\hline 6 Task orientation $\mathrm{T} 1^{\mathrm{b}}$ & .19 & .21 & $.44 * * *$ & $.50 * * *$ & $.31 * *$ & 1 & $.43 * * *$ & $.42 * * *$ & $.67 * * *$ \\
\hline 9 Task orientation $\mathrm{T} 2^{\mathrm{b}}$ & $.25^{*}$ & .19 & $.30 * *$ & $.55^{* * * *}$ & $.25^{*}$ & $.59 * * *$ & $.63 * * *$ & $.46^{* * * *}$ & 1 \\
\hline
\end{tabular}

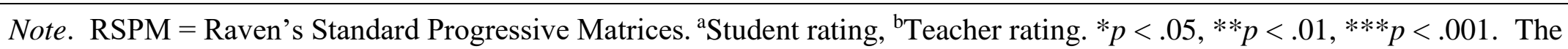
maximum number of participants in the estimation was 103 women (coverage range $=65.0 \%-97.1 \%)$ and 115 men $($ coverage range $=$ $70.4 \%-97.4 \%)$ 


\section{Table 3}

Goodness-of-fit Statistics and Akaike's and Adjusted Bayesian Information Criteria (AIC and aBIC, respectively) for the Nested Path Models on Predictive Relationships between Mathematics Performance and Student-/Teacher-Rated Task Orientation

\begin{tabular}{|c|c|c|c|c|c|c|c|c|c|c|c|}
\hline Model & $\begin{array}{l}\chi^{2}- \\
\text { value }\end{array}$ & $d f$ & $\begin{array}{l}\text { Scaling } \\
\text { correction }\end{array}$ & $\begin{array}{l}p- \\
\text { value }\end{array}$ & $\mathrm{CFI}$ & TLI & RMSEA & AIC & $\mathrm{aBIC}$ & $\begin{array}{l}\text { Model } \\
\text { comparisons }\end{array}$ & $\begin{array}{l}\chi^{2} \\
\text { difference test }{ }^{d}\end{array}$ \\
\hline $2 \mathrm{a}$ & 1.15 & 1 & 0.84 & 0.28 & 1.00 & 0.99 & 0.03 & 3320.56 & 3323.18 & 1a vs. $3 a$ & $\chi^{2}(1)=2.00, p=.16$ \\
\hline $3 a$ & 16.88 & 1 & 0.86 & 0.00 & 0.87 & 0.36 & 0.27 & 3334.18 & 3336.80 & 1a vs. $4 a$ & $\chi^{2}(2)=19.06, p=.00$ \\
\hline $4 a^{c}$ & & & & & & & & & & $3 a$ vs. $4 a$ & $\chi^{2}(1)=16.88, p=.00$ \\
\hline $1 b$ & 20.81 & 2 & 0.88 & 0.00 & 0.91 & 0.78 & 0.21 & 3589.06 & 3591.54 & $1 b$ vs. $2 b$ & $\chi^{2}(1)=15.02, p=.00$ \\
\hline $2 b$ & 6.19 & 1 & 0.92 & 0.01 & 0.98 & 0.88 & 0.16 & 3578.51 & 3581.19 & $1 \mathrm{~b}$ vs. $3 \mathrm{~b}$ & $\chi^{2}(1)=9.40, p=.00$ \\
\hline $4 b^{c}$ & & & & & & & & & & $3 \mathrm{~b}$ vs. $4 \mathrm{~b}$ & $\chi^{2}(1)=11.61, p=.00$ \\
\hline
\end{tabular}

Note. Models 1a-4a: student-rated task orientation, models 1b-4b: teacher-rated task orientation.

${ }^{\mathrm{c}}$ Model 4 is a full model. ${ }^{\mathrm{d}} \mathrm{A}$ model is improved if $p<.05$. 


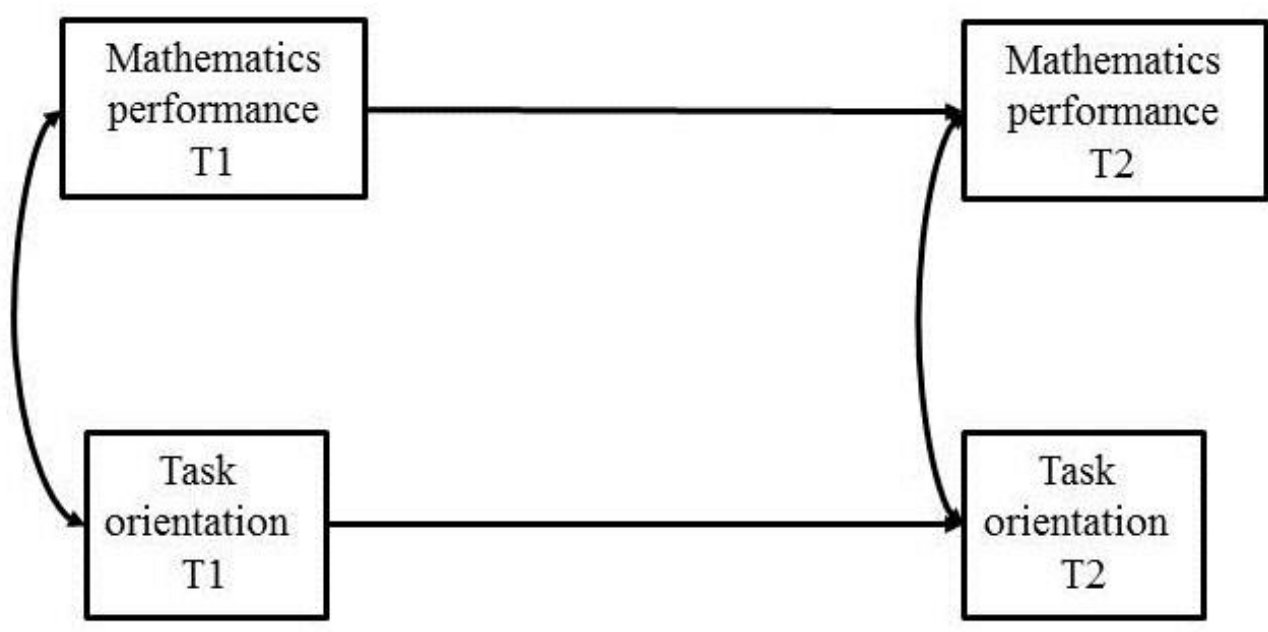

Fig. 1

Figure 1. Schematic representation of the stability model, estimated separately for student and teacher ratings

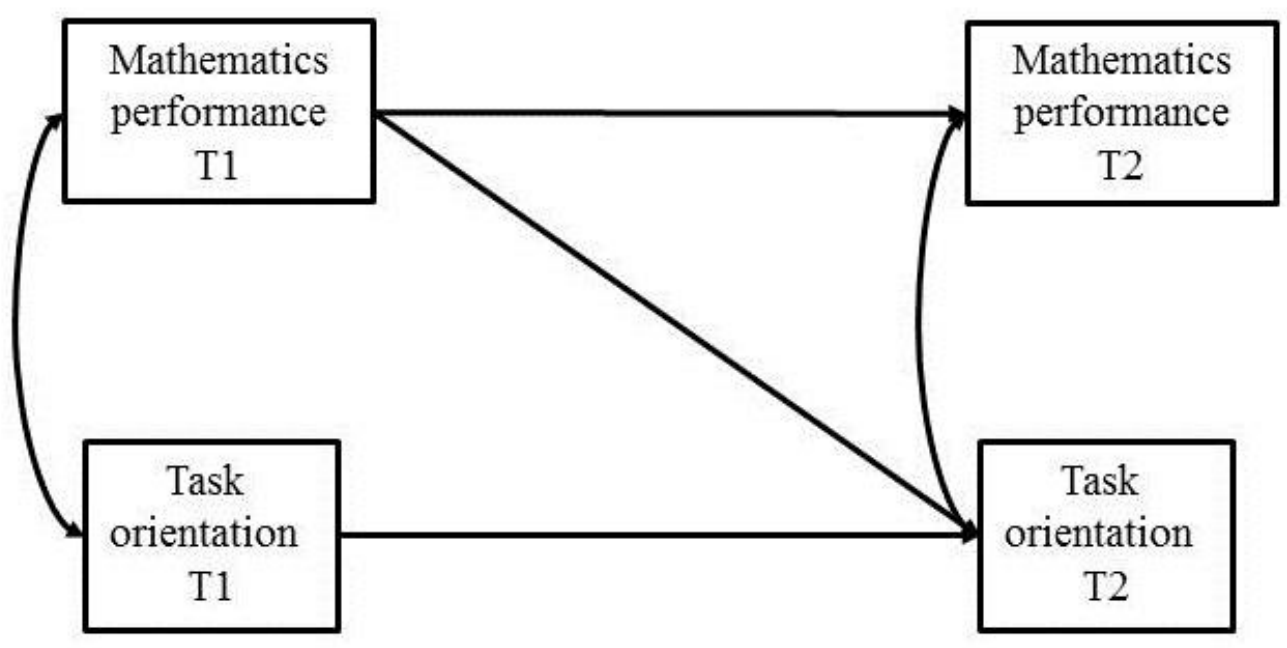

Fig. 2

Figure 2. Schematic representation of the autoregressive model for task orientation, estimated separately for student and teacher ratings 


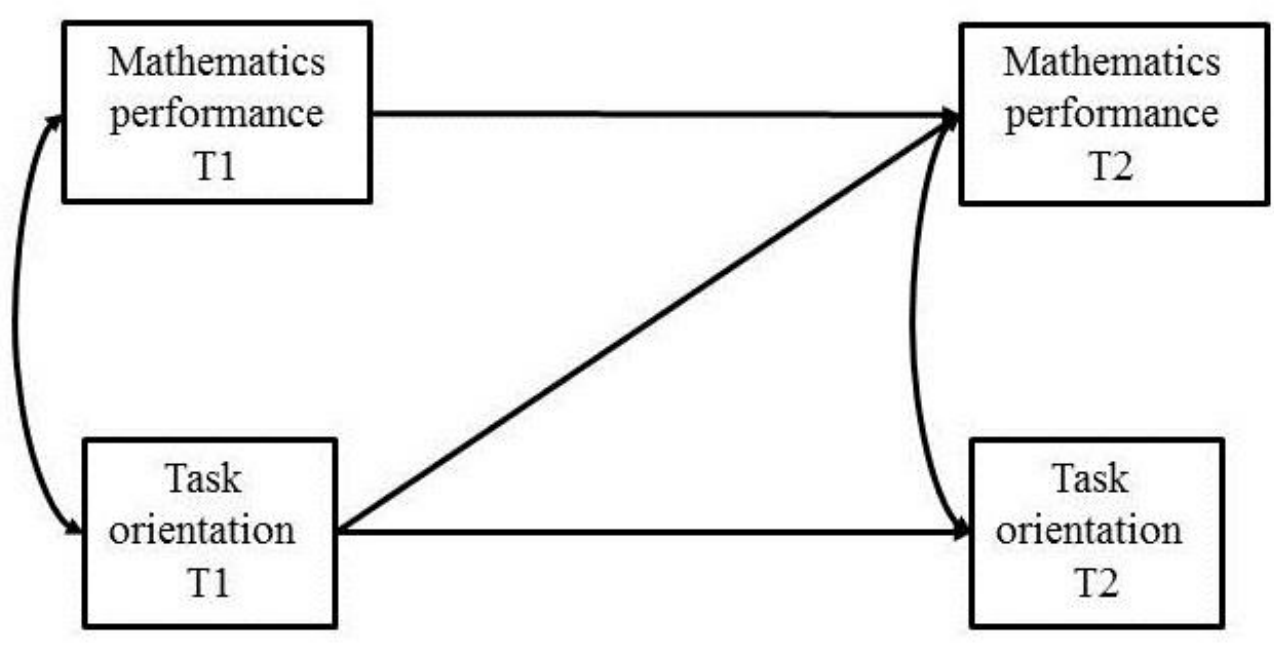

Fig. 3

Figure 3. Schematic representation of the autoregressive model for mathematics performance, separately for student and teacher ratings

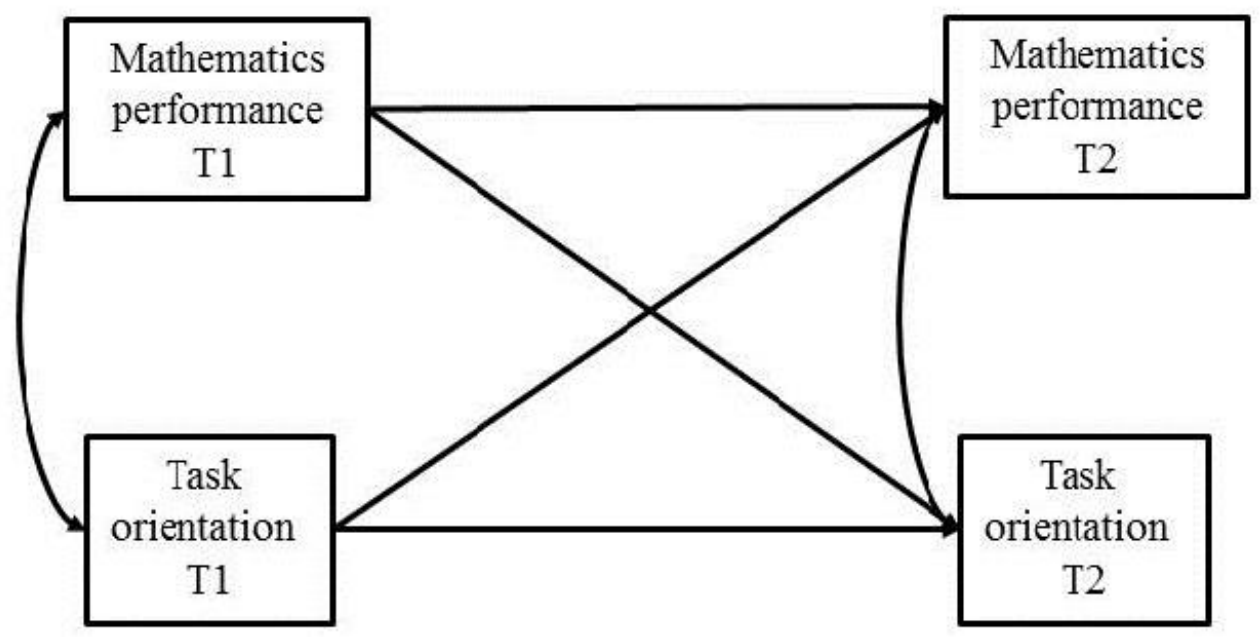

Fig. 4

Figure 4. Schematic representation of the reciprocal model with all predictive paths, estimated separately for student and teacher ratings 


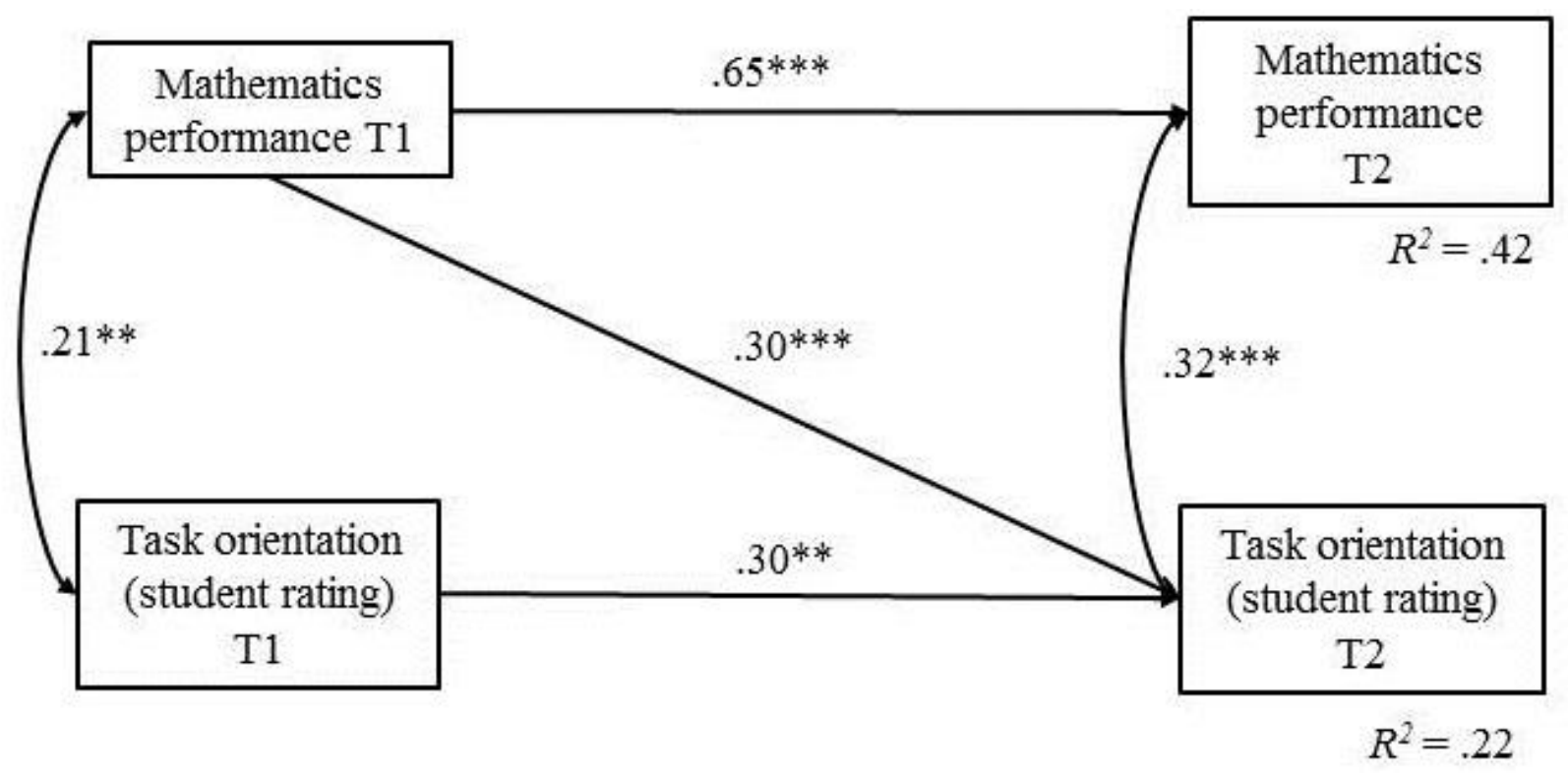

Figure 5. Final path model of the associations between mathematics performance and studentrated task orientation.

$* p<.05, * * p<.01, * * * p<.001$. 


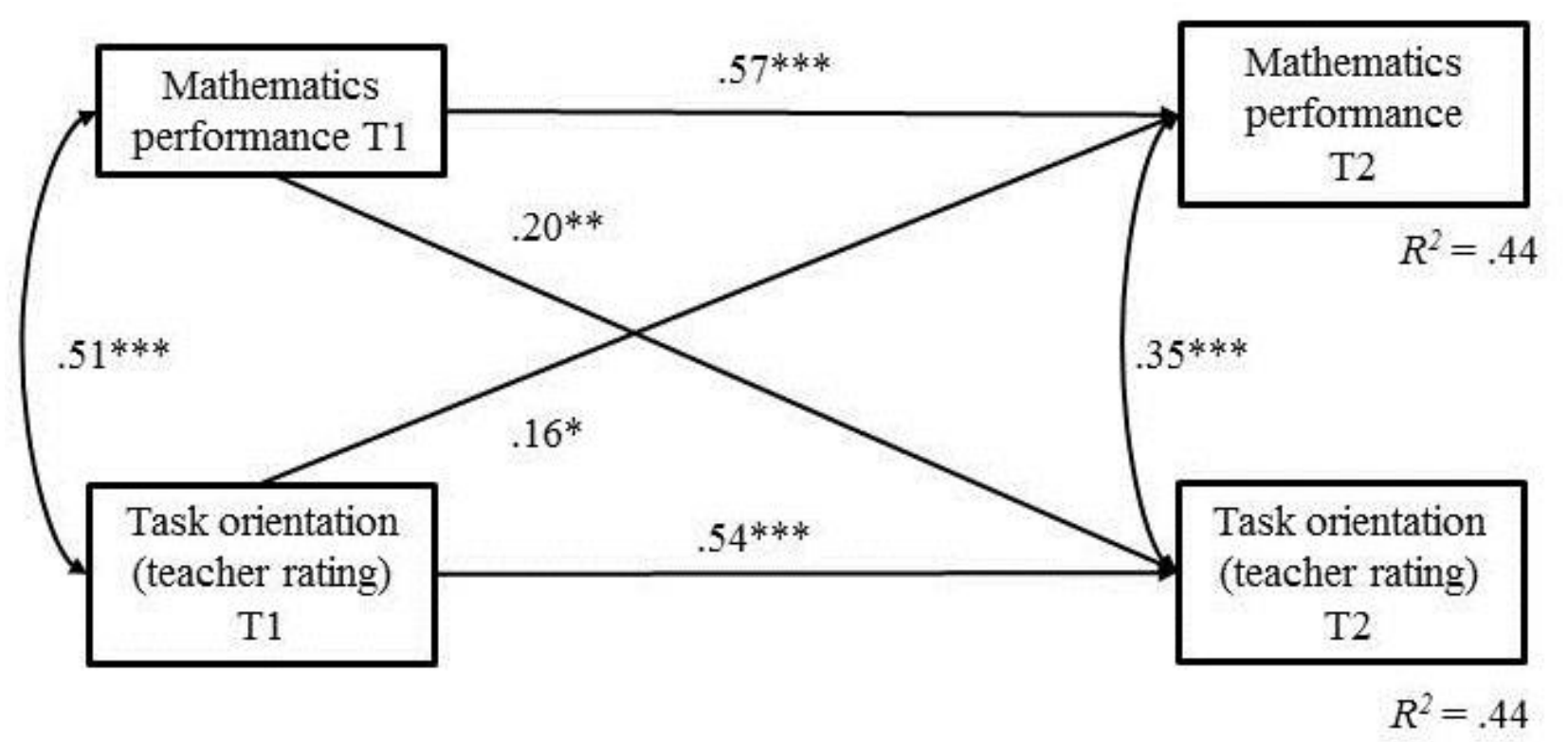

Figure 6. Final path model of the associations between mathematics performance and teacherrated task orientation. $* p<.05, * * p<.01, * * * p<.001$. 